\title{
Factors associated with hand joint destruction in Chinese patients with rheumatoid arthritis
}

Lijuan Zhang ${ }^{1,2 \dagger}$, Jing Wang ${ }^{3 \dagger}$, Qiuxiang Zhang ${ }^{1,2}$, Ting Fu ${ }^{1,2}$, Rulan Yin ${ }^{1,2}$, Ze Wang ${ }^{3}$, Liren $\mathrm{Li}^{2}$, Xianhua $\mathrm{Wu}^{3^{*}}$ and Zhifeng $\mathrm{Gu}^{1 *}$

\begin{abstract}
Background: There have been no previous report of hand joint destruction prevalence in Chinese rheumatoid arthritis (RA) patients. Therefore, the aim of this study was to investigate the prevalence and potential factors of hand joint destruction among RA patients from Nantong China. In addition, we wanted to examine the differences between functional capacity, psychological status, and quality of life in patients with hand joint destruction compared to those without hand joint destruction.

Methods: A cross-sectional study was conducted from the Affiliated Hospital of Nantong University between July 2015 and June 2016. RA patients completed questionnaires for demographic or clinical variables, the 10-cm Visual Analog Scale for pain, the 28-joint Disease Activity Score-erythrocyte sedimentation rate for disease activity, the Health Assessment Questionnaire-disability index for physical function, the Hospital Anxiety and Depression Scale for anxiety and depression, and the Short Form 36 health survey for quality of life. Laboratory examinations were taken to obtain some biochemical indicators (e.g., rheumatoid factor, anti-cyclic citrullinated peptide antibody). X-ray assessment of hand was performed and hand joint destruction was defined as Sharp score $>0$. Independent sample t-test, Mann-Whitney U-test, Chi-square test, and multivariate analysis using backward stepwise logistic regression model were used to analyze these data.
\end{abstract}

Results: One hundred and sixty-one RA patients were included in this study. Radiographic findings revealed that almost $47.2 \%(n=76)$ of patients had hand joint destruction. Multivariate analysis found that education $\leq 9$ years ( $p=0.041)$, anti-cyclic citrullinated peptide antibody positive $(p=0.021)$, high disease activity $(p=0.020)$, and long disease duration $(p<0.001)$ were important potential risk factors of hand joint destruction. Participants with hand joint destruction tended to have lower physical function and quality of life, and more severe depressive symptoms compared to individuals without hand joint destruction.

Conclusions: $47.2 \%$ of people with RA from Nantong China experienced hand joint destruction. Education, anti-cyclic citrullinated peptide antibody, disease activity, and disease duration had great impacts on hand joint destruction. The results suggested that rheumatologists should pay attention to RA patients' hand joint destruction, especially those with low education levels, anti-cyclic citrullinated peptide antibody positive, high disease activity, and long disease duration by patient education or other ways to improve patients' prognosis.

Keywords: Rheumatoid arthritis, Hand joint destruction, Disease activity, Quality of life

\footnotetext{
* Correspondence: wxh637295@sina.com; guzf@ntu.edu.cn

${ }^{\dagger}$ Equal contributors

${ }^{3}$ Department of Medical Image, Affiliated Hospital of Nantong University,

20th Xisi Road, 226001 Nantong, People's Republic of China

${ }^{1}$ Department of Rheumatology, Affiliated Hospital of Nantong University,

20th Xisi Road, 226001 Nantong, People's Republic of China

Full list of author information is available at the end of the article
}

(c) The Author(s). 2017 Open Access This article is distributed under the terms of the Creative Commons Attribution 4.0 International License (http://creativecommons.org/licenses/by/4.0/), which permits unrestricted use, distribution, and reproduction in any medium, provided you give appropriate credit to the original author(s) and the source, provide a link to the Creative Commons license, and indicate if changes were made. The Creative Commons Public Domain Dedication waiver (http://creativecommons.org/publicdomain/zero/1.0/) applies to the data made available in this article, unless otherwise stated. 


\section{Background}

As one of the most common clinical manifestations among rheumatoid arthritis (RA) patients, joint destruction is a serious threat to physical function $[1,2]$ and quality of life [3] for this population. Recent investigations have reported that people with RA have an increased risk of experiencing joint destruction with the prolongation of the course of disease [4]. This highlight the fact that joint destruction must be understood in order to inhibit radiographic progression in RA patients. Current epidemiological evidence suggested that female [5], old age [6], low body mass index (BMI) $[7,8]$, low socioeconomic status (SES) [9], less alcohol usage $[10,11]$, long disease duration $[7,12]$, high disease activity $[13,14]$, and comorbidities $[15,16]$ were associated with joint destruction. For many years, rheumatoid factor (RF) [17-20] and anti-citrullinated peptide (CCP) antibody [21-23] have been regarded as important risk factors for joint destruction in RA patients. Additionally, drug treatments play important roles in preventing RA patients from joint destruction [24-26]. Therefore, we were specifically interested in the association between those variables and hand joint destruction. However, there have been no previous report of hand joint destruction prevalence in Chinese RA patients. Thus, the aim of this study was to explore the prevalence and potential risk factors of hand joint destruction among RA patients from Nantong China. In addition, we wanted to examine the differences between functional capacity, psychological status, and quality of life in patients with hand joint destruction compared to those without hand joint destruction.

\section{Methods}

\section{Patients}

All patients fulfilled the 1987 revised criteria of the American College of Rheumatology (ACR) [27] or 2010/ 2012 ACR classification criteria [28, 29] for RA. They were recruited from the Affiliated Hospital of Nantong University between July 2015 and June 2016. RA patients enrolled during study period were all patients who visited their rheumatology clinic (outpatient or inpatient department). Patients included in this study were treated in accordance with the $2008 \mathrm{ACR}$ recommendations for the management of RA [30]. Patients meeting the following exclusion criteria were excluded: (1) they aged less than 18 years old; (2) they could not complete the questionnaires; (3) they had specific comorbidities including renal, serious cardiac, liver diseases or malignancy that could influence their quality of life; (4) they could not complete the measurements of hand joint destruction, disease activity or pain. This cross-sectional study was approved by the Affiliated Hospital of Nantong University, and a written informed consent was obtained from each RA patient according to the Declaration of Helsinki.

\section{Demographic and clinical characteristics}

Demographic and clinical data included gender, age (years), BMI $\left(\mathrm{kg} / \mathrm{m}^{2}\right)$, education (years), employment status, income/person/month (USD), personal health insurance, tobacco and alcohol usage, comorbidities (e.g., hypertension), and disease duration (years). Several serological markers including C-reactive protein (CRP), erythrocyte sedimentation rate (ESR), RF and anti-CCP antibody were examined in this study. We evaluated disease activity using the 28-joint Disease Activity ScoreESR (DAS28-ESR) [31]. All demographic, clinical, laboratory data and radiographs were collected at the same time point. We gained the personal medication by querying the electronic medical records and patients' self-reports, including the usages of disease-modifying antirheumatic drugs (DMARDs), corticosteroids and biologics from the past six months to the date of radiographs.

\section{Assessment of patient-reported outcomes}

Patients' pain was assessed by the $10-\mathrm{cm}$ visual analog scale (VAS) $(0=$ no pain, and $10=$ most severe pain $)$ [32]; The Health Assessment Questionnaire-disability index (HAQ-DI) was used to assess physical function [33]; As described previously [34], the Hospital Anxiety and Depression Scale (HADS), a 14-item questionnaire, was used to assess levels of anxiety and depression. Anxiety and depression are scored separately using the 7 item subscales (scores range from 0-21, with higher scores indicating more severe mood disorders). As described previously [35], quality of life was assessed using the Short Form 36 health survey (SF-36), which assesses eight domains (scores range from 0-100, with higher scores indicating better health status): physical functioning (PF), role physical (RP), bodily pain (BP), general health $(\mathrm{GH})$, vitality $(\mathrm{VT})$, social functioning $(\mathrm{SF})$, role emotional (RE), and mental health (MH). Z-transformed and normalized domain scores are grouped into Physical Component Summary (PCS) and Mental Component Summary (MCS) scores.

\section{Radiographic assessments}

All radiographs were scored in accordance with the van der Heijde-modified Sharp Score of hands by two experienced investigators (GZ and WXH) who were not aware of the patients' clinical findings [36, 37]. The total score for the hands, including the wrists, 10 metacarpophalangeal joints (MCPJs), and 10 proximal interphalangeal joints (PIPJs), ranged from 0 to 157, with the erosion score (E score) ranging from 0 to 85 , and the joint space narrowing score (JSN score) ranging 
from 0 to 72 . Hand joint destruction was categorized as following: normal (Sharp score $=0$ ), abnormal (Sharp score $>0$ ).

\section{Data collection}

Questionnaires and some measurements were administered to patients from July 2015 to June 2016. The written questionnaire was completed by the patients with the physician present or the questionnaire was completed by the physician asking the patients questions (an interview-led questionnaire) in a clinical setting. The same clinician evaluated DAS28-ESR for all patients. After finishing data collection, nurses would calculate the results. Two research assistants added the results to a computer database by double checked against the original data.

\section{Statistical analysis}

Because there were two patients lacking some sociodemographic data in this study, we used multiple imputation (MI) to handle missing data. As described previously [38], MI is a general approach to the problem of missing data that is available in several commonly used statistical packages. The first stage is to create multiple copies of the dataset, with the missing values replaced by imputed values. The second stage is to use standard statistical methods to fit the model of interest to each of the imputed datasets. In this study, i) five imputed datasets were created, ii) the multiple imputation procedure in SAS statistical software (PROC MI) was used to impute the missing data and iii) employment status, education and tobacco usage were included in the imputation models.

We conducted descriptive analyses to investigate the patients' characteristics. Continuous and normally distributed variables were presented as means and standard deviation (SD) and independent sample $t$-test was used to assess group differences. Not normally distributed data was described by median and interquartile range (IQR) and Mann-Whitney $U$-test was used to assess group differences. Descriptive statistics also involved frequencies (\%) for categorical variables and the chi-square test was used to assess group differences. Variables shown to be significant in the independent sample $t$-test, Mann-Whitney $U$-test or chi-square test were included in the multivariate analysis using backward stepwise logistic regression model to investigate the potential risk factors of hand joint destruction with odds ratios (ORs), and the corresponding 95\% confidence intervals (CIs). The backward stepwise logistic regression model fit was evaluated by the HosmerLemeshow goodness-of-fit test. Statistical significance was considered when $p<0.05$ (two-sided). Data were analyzed using SPSS (version 20.0).

\section{Results}

\section{Patient characteristics}

Fourteen RA patients met the exclusion criteria, resulting in the enrollment of $161 \mathrm{RA}$ patients in the current study, of which 48 patients were inpatients (Fig. 1). Table 1 presented the baseline participant characteristics included in our analysis. The mean (SD) age of the respondents was 53.7 (12.9) years, and $83.9 \%$ were female. The median (IQR) of disease duration and DAS28-ESR were 4.1 (9) years and 3.3 (1.7), respectively. Almost $94.4 \%$ of patients were treated with DMARDs. There were $67.7 \%$ of patients who were RF positive and $64.6 \%$ of patients who were anti-CCP antibody positive. Radiographic finding revealed that almost $47.2 \% \quad(n=76)$ of individuals in the sample group had hand joint destruction. The range of Sharp scores in the patients with hand joint destruction was from 1 to 117 .

\section{Differences between demographic and clinical variables in patients with hand joint destruction compared to those without hand joint destruction}

As shown in Table 1, a number of demographic and clinical variables were tested for possible differences in patients with hand joint destruction compared to those without hand joint destruction. The patients were

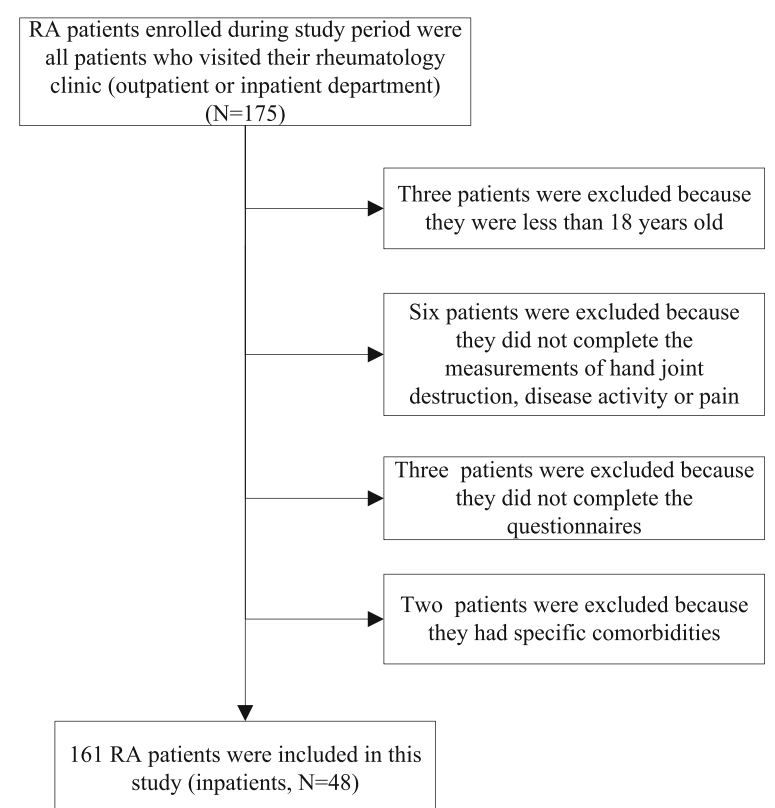

Fig. 1 "Flow chart of the study" 
Table 1 Differences between demographic and clinical variables in patients with hand joint destruction compared to those without hand joint destruction

\begin{tabular}{|c|c|c|c|c|c|}
\hline Variables & $\begin{array}{l}\text { Overall sample } \\
(N=161)\end{array}$ & $\begin{array}{l}\text { Non-hand joint destruction } \\
(\text { Sharp score }=0 ; N=85)\end{array}$ & $\begin{array}{l}\text { Hand joint destruction } \\
\text { (Sharp score }>0 ; N=76)\end{array}$ & $x^{2} / t / z$ & $P$-value \\
\hline \multicolumn{6}{|l|}{ Demographic factors } \\
\hline Female gender, no. (\%) & $135(83.9)$ & $69(81.2)$ & $66(86.8)$ & $0.95^{*}$ & 0.329 \\
\hline Age, mean (SD) years & $53.7(12.9)$ & $52.7(13.7)$ & $54.8(12.1)$ & $-1.03^{* *}$ & 0.303 \\
\hline BMl, mean (SD) kg/m² & $22.0(3.4)$ & $22.3(3.3)$ & $21.6(3.5)$ & $-1.29^{* *}$ & 0.198 \\
\hline Education, years, no. (\%) & & & & $5.58^{*}$ & 0.018 \\
\hline$\leq 9$ years & $122(75.8)$ & $58(68.2)$ & $64(84.2)$ & & \\
\hline$>9$ years & $39(24.2)$ & $27(31.8)$ & $12(15.8)$ & & \\
\hline Employment status, no. (\%) & & & & $0.01^{*}$ & 0.946 \\
\hline Employed & $97(60.2)$ & $51(60)$ & $46(60.5)$ & & \\
\hline Unemployed & $64(39.8)$ & $34(40)$ & $30(39.5)$ & & \\
\hline Income/person/month, USD, no. (\%) & & & & $0.28^{*}$ & 0.599 \\
\hline$\leq 435$ USD & $144(89.4)$ & $75(88.2)$ & $69(90.8)$ & & \\
\hline$>435$ USD & $17(10.6)$ & $10(11.8)$ & $7(9.2)$ & & \\
\hline Personal health insurance, no. (\%) & & & & $0.07^{*}$ & 0.785 \\
\hline Yes & $117(72.7)$ & $61(71.8)$ & $56(73.7)$ & & \\
\hline No & $44(27.3)$ & $24(28.2)$ & $20(26.3)$ & & \\
\hline Tobacco usage, no. (\%) & & & & $2.42^{*}$ & 0.120 \\
\hline Yes & $17(10.6)$ & $12(14.1)$ & $5(6.6)$ & & \\
\hline No & $144(89.4)$ & $73(85.9)$ & $71(93.4)$ & & \\
\hline Alcohol usage, no. (\%) & & & & $1.66^{*}$ & 0.197 \\
\hline Yes & $23(14.3)$ & $15(17.6)$ & $8(10.6)$ & & \\
\hline No & $138(85.7)$ & $70(82.4)$ & $68(89.4)$ & & \\
\hline \multicolumn{6}{|l|}{ Clinical factors } \\
\hline Comorbidities, yes, no. (\%) & & & & $2.34^{*}$ & 0.127 \\
\hline Yes & $34(21.1)$ & $14(16.5)$ & $20(26.3)$ & & \\
\hline No & $127(78.9)$ & $71(83.5)$ & $56(73.7)$ & & \\
\hline Disease duration, median (IQR) years & $4.1(9)$ & $2(4.5)$ & $9.5(13.5)$ & -6.64 & $<0.001$ \\
\hline VAS pain (range $0-10$ ), median (IQR) & $5(6)$ & $3(6)$ & $5(6.5)$ & -1.05 & 0.294 \\
\hline DAS28-ESR, median (IQR) & $3.3(1.7)$ & $2.9(1.6)$ & $3.6(1.8)$ & -3.35 & 0.001 \\
\hline DMARDs usage, no. (\%) & & & & $4.98^{*}$ & 0.026 \\
\hline Yes & $152(94.4)$ & 77 (90.6) & 75 (98.7) & & \\
\hline No & $9(5.6)$ & $8(9.4)$ & $1(1.3)$ & & \\
\hline Corticosteroids usage, no. (\%) & & & & $9.32^{*}$ & 0.002 \\
\hline Yes & $92(57.1)$ & $39(45.9)$ & $53(69.7)$ & & \\
\hline No & $69(42.9)$ & $46(54.1)$ & $23(30.3)$ & & \\
\hline Biologics usage, no. (\%) & & & & $0.02^{*}$ & 0.889 \\
\hline Yes & $11(6.8)$ & $3(3.5)$ & $3(3.9)$ & & \\
\hline No & $150(93.2)$ & $82(96.5)$ & $73(96.1)$ & & \\
\hline ESR, median (IQR) mm/h & $22(38)$ & $20(35.5)$ & $23.5(50.5)$ & -0.90 & 0.367 \\
\hline CRP, median (IQR) mg/l & $7.5(12.4)$ & $5.9(13.6)$ & $8.2(20.6)$ & -1.60 & 0.110 \\
\hline RF positive, no. (\%) & & & & $12.68^{*}$ & $<0.001$ \\
\hline Yes & $109(67.7)$ & $47(55.3)$ & $62(81.9)$ & & \\
\hline No & $52(32.3)$ & $38(44.7)$ & $14(18.1)$ & & \\
\hline
\end{tabular}


Table 1 Differences between demographic and clinical variables in patients with hand joint destruction compared to those without hand joint destruction (Continued)

\begin{tabular}{|c|c|c|c|c|c|}
\hline Anti-CCP antibody positive, no. (\%) & & & & $15.45^{*}$ & $<0.001$ \\
\hline Yes & $104(64.6)$ & $43(50.6)$ & $61(80.3)$ & & \\
\hline No & $57(35.4)$ & $42(49.4)$ & $15(19.7)$ & & \\
\hline
\end{tabular}

$I Q R$ Interquartile range, $B M I$ body mass index, VAS visual analog scale, DAS28 Disease Activity Score in 28 joints, DMARDs disease-modifying antirheumatic drugs, ESR erythrocyte sedimentation rate, $C R P$ C-reactive protein, $R F$ rheumatoid factor, Anti-CCP anti-cyclic citrullinated peptide ${ }^{*}$ Chi-square test

*** Independent t-tests

divided into two groups according to Sharp score. Patients with hand joint destruction tended to have lower education level $(\leq 9$ years $)(p=0.018)$, longer disease duration $(p<0.001)$, higher disease activity $(p=0.001)$, DMARDs usage $(p=0.026)$, corticosteroids usage $(p=$ $0.002)$, RF positive $(p<0.001)$, and anti-CCP antibody positive $(p<0.001)$ compared to patients without hand joint destruction. However, no statistically significant associations were found with regard to comorbidities $(p=$ $0.127)$, VAS pain $(p=0.294)$, biologics usage $(p=0.889)$, $\operatorname{ESR}(p=0.367)$, and CRP $(p=0.110)$.

\section{Multivariate analysis using backward stepwise logistic regression model for hand joint destruction}

We used the multivariate analysis using backward stepwise logistic regression model to investigate the potential risk factors of hand joint destruction, as indicated in Table 2. The result of final step indicated that low education level ( $\leq 9$ years) (OR: $3.06 ; p=0.041)$, antiCCP antibody positive (OR: $1.07 ; p=0.021$ ), high disease activity (OR: $1.45 ; p=0.020$ ), and long disease duration (OR: $1.21 ; p<0.001)$ were the potential risk factors of hand joint destruction in RA patients from Nantong China. The model (step 2) had a good fit under the Hosmer- Lemeshow goodness-of-fit test $\left(R^{2}=0.379\right.$, $\chi^{2}=8.26, p=0.411$ ).

\section{Differences between functional capacity, psychological status, and quality of life in patients with hand joint destruction compared to those without hand joint destruction}

We found that the HAQ-DI and HADS-depression scores in individuals with hand joint destruction were significantly higher compared to individuals without hand joint destruction. However, expect the PF $(p=0.012)$, no statistically significant association was found with regard to other dimension scores of SF-36 (Table 3).

\section{Discussion}

To our knowledge, this is the first study investigating the prevalence and potential risk factors (e.g., education, anti-CCP antibody) of hand joint destruction in RA patients from Nantong China. As described

Table 2 Results of multivariate analysis using backward stepwise logistic regression model in patients with hand joint destruction

\begin{tabular}{|c|c|c|c|c|c|c|c|c|}
\hline \multirow[t]{2}{*}{ Variables } & & \multirow[t]{2}{*}{ B } & \multirow[t]{2}{*}{ SE } & \multirow[t]{2}{*}{ Wald } & \multirow[t]{2}{*}{ OR } & \multicolumn{2}{|l|}{ OR 95\% Cl } & \multirow[t]{2}{*}{$P$-value } \\
\hline & & & & & & Lower bound & Upper bound & \\
\hline \multirow[t]{7}{*}{ Step 1} & Education $\leq 9$ years & 1.11 & 0.54 & 4.26 & 3.01 & 1.16 & 7.64 & 0.038 \\
\hline & Disease duration, years & 0.18 & 0.05 & 20.37 & 1.22 & 1.13 & 1.51 & $<0.001$ \\
\hline & DAS28-ESR & 0.39 & 0.16 & 5.30 & 1.46 & 1.06 & 2.15 & 0.022 \\
\hline & DMARDs usage, yes & -2.24 & 1.28 & 3.11 & 0.13 & 0.04 & 1.37 & 0.077 \\
\hline & Corticosteroids usage, yes & -0.76 & 0.45 & 3.06 & 0.48 & 0.21 & 1.09 & 0.080 \\
\hline & RF positive, yes & -0.66 & 0.39 & 2.79 & 0.63 & 0.13 & 1.74 & 0.095 \\
\hline & Anti-CCP antibody positive, yes & -0.97 & 0.46 & 5.02 & 1.03 & 0.17 & 1.57 & 0.025 \\
\hline$R^{2}$ & & 0.380 & & & & & & \\
\hline \multirow[t]{4}{*}{ Step 2} & Education $\leq 9$ years & 1.11 & 0.55 & 4.24 & 3.06 & 1.1 & 8.41 & 0.041 \\
\hline & Disease duration, years & 0.20 & 0.05 & 21.26 & 1.21 & 1.12 & 1.32 & $<0.001$ \\
\hline & DAS28-ESR & 0.38 & 0.16 & 5.43 & 1.45 & 1.16 & 2.17 & 0.020 \\
\hline & Anti-CCP antibody positive, yes & -0.99 & 0.47 & 5.12 & 1.07 & 0.16 & 1.68 & 0.021 \\
\hline$R^{2}$ & & 0.379 & & & & & & \\
\hline
\end{tabular}


Table 3 Differences between patient-reported outcomes in patients with hand joint destruction compared to those without hand joint destruction

\begin{tabular}{|c|c|c|c|c|c|}
\hline Variables & $\begin{array}{l}\text { Overall sample } \\
(N=161)\end{array}$ & $\begin{array}{l}\text { Non-hand joint destruction } \\
\text { (Sharp score }=0 ; N=85 \text { ) }\end{array}$ & $\begin{array}{l}\text { Hand joint destruction } \\
\text { (Sharp score }>0 ; N=76)\end{array}$ & z & $P$-value \\
\hline HAQ-DI score (range 0-3), median (IQR) & $0.15(0.88)$ & $0.05(0.55)$ & $0.25(1.26)$ & -3.62 & $<0.001$ \\
\hline HADS-anxiety score (range 0-21), median (IQR) & $5(3)$ & $5(6)$ & $5(5)$ & -0.57 & 0.571 \\
\hline HADS-depression score (range 0-21), median (IQR) & $5(5)$ & $3(4.5)$ & $6(6)$ & -1.50 & 0.047 \\
\hline \multicolumn{6}{|l|}{ Domains of SF-36 scores (range 0-100), median (IQR) } \\
\hline PCS & $37.75(35.25)$ & $38(32.75)$ & $36.63(34.13)$ & -1.34 & 0.180 \\
\hline MCS & $58.13(35.13)$ & $59.63(36.5)$ & $56.96(34.22)$ & -0.80 & 0.423 \\
\hline PF & $60(47.5)$ & $65(52.5)$ & $55(55)$ & -2.50 & 0.012 \\
\hline RP & $0(25)$ & $0(25)$ & $0(25)$ & -0.22 & 0.830 \\
\hline $\mathrm{BP}$ & $41(43.5)$ & $52(42)$ & 41 (51.5) & -0.78 & 0.434 \\
\hline $\mathrm{GH}$ & $40(32)$ & $42(31.5)$ & $40(30)$ & -1.44 & 0.106 \\
\hline VT & $55(20)$ & $55(22.5)$ & $60(20)$ & -0.32 & 0.752 \\
\hline SF & $62.5(50)$ & $62.5(50)$ & 62.5 (46.88) & -1.26 & 0.208 \\
\hline RE & $33.3(100)$ & $66.7(100)$ & $33.3(100)$ & -0.32 & 0.752 \\
\hline $\mathrm{MH}$ & $64(24)$ & $68(24)$ & $64(24)$ & -0.30 & 0.761 \\
\hline
\end{tabular}

$I Q R$ Interquartile range, $H A Q-D I$ health assessment questionnaire-disability index, HADS Hospital Anxiety and Depression Scale, SF-36 Short Form 36 health survey, $P C S$ physical components summary, MCS mental components summary, PF physical functioning, RP role physical, $B P$ body pain, $G H$ general health, VT vitality, $S F$ social functioning, RE role emotional, $M H$ mental health

previously [39], x-ray assessment of hand/wrist was repeated at baseline and the 12th month and a change of total Sharp score $>0.5$ units was defined as radiographic progression. Because this study was cross-sectional in design, we defined hand joint destruction according to the van der Heijde-modified Sharp Score and their cutoff value was 0 , which was a quite understandable indicator for hand joint destruction. In the current study, almost $47.2 \%$ of RA patients from Nantong China suffered from hand joint destruction. This prevalence estimate is significantly lower than those observed both in China [39] and other countries [5]. Such discrepancy could be explained that the majority of RA patients included in this study were outpatients with milder disease, which would have led to a lower prevalence estimate.

Previous studies have reported that female [5], older age [6], and less alcohol usage $[10,11]$ were associated with joint destruction. However, our study demonstrated that there were no correlation between these variables and hand joint destruction. One possible explanation for the different results is the existence of cultural diversity between Chinese and Western population. It must be noted that there was no association between BMI and hand joint destruction in this study, which was in contrast with previous meta-analysis reporting that obesity $\left(\mathrm{BMI}>30 \mathrm{~kg} / \mathrm{m}^{2}\right)$ was associated with lower radiographic joint damage in RA [8]. It could be explained that the mean BMI $\left(22 \mathrm{~kg} / \mathrm{m}^{2}\right)$ in this study was much lower than that in previous study [8]. Furthermore, we reported that comorbidities were not associated with hand joint destruction, which was in contrast with previous studies $[15,16]$. This differences might be explained that certain patients with comorbidities were excluded in this study. Additionally, it is well known that SES is multifactor (e.g., education, income) and low SES could result in joint destruction in RA patients [9]. Our study also demonstrated that there were significant correlation between low education level and hand joint destruction. It might be explained that patients with low education levels tended to have low medication adherence rates [40], which could result in hand joint destruction.

Not surprisingly, disease duration was significantly associated with hand joint destruction in RA patients from Nantong China, which was in line with previous studies $[7,12,19]$. When RA progresses, the joints will be more and more affected (e.g., bone erosion), which possibly result in hand joint destruction. We also found that disease activity was significantly associated with hand joint destruction, which was similar to previous studies $[13,14]$. Our group has reported that about $57 \%$ patients tended to take 2-3 DMARDs in Chinese RA patients [40]. In the current study, we reported that DMARDs usage had a positive correlation with hand joint destruction. It might be explained that those using more than one DMARDs could be patients with more severe disease, which could lead to more severe joint destruction [41-44]. In contrast with previous meta-analysis [45], we found that corticosteroids usage was positively associated with hand joint destruction, which might be 
explained that RA patients using corticosteroids might be those with difficult to control inflammation, or who could not take DMARDs. In addition, we reported that only $6.8 \%$ of RA patients from Nantong China used biologics. The proportion of biologics usage is much lower than that in previous studies from other countries [46, 47]. It could be explained that Chinese RA patients with low SES cannot afford the costs of biologics, which are expensive and cannot be reimbursed by person health insurance. In accordance with previous studies [18, 19, 21-23], our study demonstrated significant correlations among RF, anti-CCP antibody, and hand joint destruction, which could be explained that RF and anti-CCP antibody positive were both important predictors of structural progression in RA patients. However, some analysis reported a higher correlation of anti-CCP antibody with joint damage than of RF $[21,23]$. Therefore, to identify which variables were most significantly correlated with hand joint destruction, the multivariate analysis using backward stepwise logistic regression model was used. We found that education $\leq 9$ years, anti-CCP antibody positive, high disease activity, and longer disease duration were the potential risk factors for hand joint destruction.

There are, however, additional important shortcomings in this study that need to be addressed. First, all patients involved in this investigation were only from one center and the sample size was relatively small, so generalization of the findings to other population should be cautious. In addition, the majority of patients were female and some of them were inpatients, therefore, our sample was not representative of the Chinese RA population. Another problem with the sampling method was that some patients with milder disease might be missed (less likely to be an inpatient, less likely to be attending outpatient reviews very often, so therefore possibly less likely to be invited to participate in this study). Second, the inter-rater reliability of Sharp score also could not be tested. However, to ensure the accuracy of Sharp score for the hands, two experienced observers evaluated hand joint destruction according to the HSS at the same time, and all readers were blind to the results. Third, all patients were heterogeneous in disease duration, which could result in selection bias. Therefore, more detailed analysis was needed to address the potential risk factors such as early diagnosis and immediate treatment for early radiographic changes of hands in RA patients. Fourth, slightly different methods were used to complete the questionnaires (patients completed with physician present versus physician-led completion) in this study, which might have introduced measurement bias. However, the survey interviewers were professionally trained in order to reduce this bias. Finally, causal conclusion could not be inferred because this study was cross-sectional in design.

\section{Conclusions}

47.2\% of people with RA from Nantong China experienced hand joint destruction. Education, anti-CCP antibody, disease activity, and disease duration played important roles in the prevalence of hand joint destruction. The results suggested that rheumatologists should pay attention to RA patients' hand joint destruction, especially those with low education levels, anti-CCP antibody positive, high disease activity, and long disease duration by patient education or other ways to improve patients' prognosis.

\section{Abbreviations}

ACR: American College of Rheumatology; anti-CCP: Anti-Cyclic Citrullinated Peptide; BMl: Body mass index; BP: Body pain; Cl: Confidence intervals; CRP: C-reactive protein; DAS28: Disease activity score in 28 joints; DMARDs: Disease-modifying antirheumatic drugs; ESR: Erythrocyte sedimentation rate; GH: General health; HADS: Hospital Anxiety and Depression Scale; HAQ-DI: Health Assessment Questionnaire-disability index; IQR: Interquartile range; JSN: Joint space narrowing; MCS: Mental Component Summary; MCPJs: Metacarpophalangeal joints; MH: Mental health;

Ml: Multiple imputation; OR: Odds ratio; PCS: Physical Component Summary; PIPJs: Proximal interphalangeal joints; PF: Physical function; RA: Rheumatoid arthritis; RE: Role emotional; RF: Rheumatoid factor; RP: Role physical; SD: Standard deviation; SES: Socioeconomic status; SF: Social function; SF36: The Short Form 36 Health survey; VAS: Visual analog scale; VT: Vitality

\section{Acknowledgments}

We would like to thank Alick Zack for his assistance with this study.

\section{Funding}

This study was supported by Grants from the Chinese National Natural Science Foundation (Grant no. 81671616 and 81471603); Jiangsu Provincial Commission of Health and Family Planning Foundation (Grant no. H201317 and H201623); Science Foundation of Nantong City (Grant no. MS32015021, MS2201564 and MS22016028); Science and Technology Foundation of Nantong City (Grant no. HS2014071 and HS2016003); the College graduate research and innovation of Jiangsu Province (Grant no. KYZZ15_0353 and KYZZ16_0358).

\section{Availability of data and materials}

The majority of data generated or analyzed during this study are included in this published article. Remaining data not published here are available from the corresponding author on reasonable request.

\section{Authors' contributions}

LZ and JW have contributed to study design, data collection, data analysis, interpretation of results, and preparation of the manuscript. LZ and JW contributed equally to this work. QZ, TF, RY, ZW, and LL have contributed to revision of this manuscript; XW and ZG have contributed to study design, preparation of the manuscript. All authors read and approved the final manuscript.

\section{Competing interests}

The authors declared that they have no competing interests.

\section{Consent for publication}

Not applicable.

\section{Ethics approval and consent to participate}

The study was approved by the Ethics Committee of the Affiliated Hospital of Nantong University, and written informed consents were obtained from all of the participants, according to the Declaration of Helsinki. 


\section{Publisher's Note}

Springer Nature remains neutral with regard to jurisdictional claims in published maps and institutional affiliations.

\begin{abstract}
Author details
'Department of Rheumatology, Affiliated Hospital of Nantong University, 20th Xisi Road, 226001 Nantong, People's Republic of China. ${ }^{2}$ School of Nursing, Nantong University, 19th Qixiu Road, 226001 Nantong, People's Republic of China. ${ }^{3}$ Department of Medical Image, Affiliated Hospital of Nantong University, 20th Xisi Road, 226001 Nantong, People's Republic of China.
\end{abstract}

Received: 12 January 2017 Accepted: 4 May 2017

Published online: 22 May 2017

\section{References}

1. Sugihara T, Ishizaki T, Hosoya T, et al. Structural and functional outcomes of a therapeutic strategy targeting low disease activity in patients with elderlyonset rheumatoid arthritis: a prospective cohort study (CRANE). Rheumatology (Oxford). 2015;54(5):798-807.

2. van den Broek $M$, Dirven $L$, de Vries-Bouwstra JK, et al. Rapid radiological progression in the first year of early rheumatoid arthritis is predictive of disability and joint damage progression during 8 years of follow-up. Ann Rheum Dis. 2012;71(9):1530-3.

3. Emery P, Kavanaugh A, Bao Y, et al. Comprehensive disease control (CDC): what does achieving CDC mean for patients with rheumatoid arthritis? Ann Rheum Dis. 2015;74(12):2165-74.

4. Suto T, Okamura K, Yonemoto $Y$, et al. Prediction of Large Joint Destruction in Patients With Rheumatoid Arthritis Using 18 F-FDG PET/CT and Disease Activity Score. Medicine (Baltimore). 2016;95(7):e2841.

5. Syversen SW, Gaarder PI, Goll GL, et al. High anti-cyclic citrullinated peptide levels and an algorithm of four variables predict radiographic progression in patients with rheumatoid arthritis: results from a 10-year longitudinal study. Ann Rheum Dis. 2008;67(2):212-7.

6. Mangnus L, van Steenbergen HW, Lindqvist E, et al. Studies on ageing and the severity of radiographic joint damage in rheumatoid arthritis. Arthritis Res Ther. 2015;17:222.

7. Ickinger C, Musenge E, Tikly M. Patterns and predictors of joint damage as assessed by the rheumatoid arthritis articular damage (RAAD) score in South Africans with established rheumatoid arthritis. Clin Rheumatol. 2013; 32(12):1711-7.

8. Vidal C, Barnetche T, Morel J, et al. Association of Body Mass Index Categories with Disease Activity and Radiographic Joint Damage in Rheumatoid Arthritis: A Systematic Review and Metaanalysis. J Rheumatol. 2015;42(12):2261-9.

9. Molina E, Del Rincon I, Restrepo JF, et al. Association of socioeconomic status with treatment delays, disease activity, joint damage, and disability in rheumatoid arthritis. Arthritis Care Res (Hoboken). 2015;67(7):940-6.

10. Davis ML, Michaud K, Sayles H, et al. Associations of alcohol use with radiographic disease progression in African Americans with recent-onset rheumatoid arthritis. J Rheumatol. 2013:40(9):1498-504.

11. Nissen MJ, Gabay C, Scherer A, et al. The effect of alcohol on radiographic progression in rheumatoid arthritis. Arthritis Rheum. 2010;62(5):1265-72.

12. Renner N, Kronke G, Rech J, et al. Anti-citrullinated protein antibody positivity correlates with cartilage damage and proteoglycan levels in patients with rheumatoid arthritis in the hand joints. Arthritis Rheumatol. 2014;66(12):3283-8

13. Drossaers-Bakker KW, de Buck M, van Zeben D, et al. Long-term course and outcome of functional capacity in rheumatoid arthritis: the effect of disease activity and radiologic damage over time. Arthritis Rheum. 1999;42(9):1854-60.

14. Smolen JS, Van Der Heijde DM, St Clair EW, et al. Predictors of joint damage in patients with early rheumatoid arthritis treated with high-dose methotrexate with or without concomitant infliximab: results from the ASPIRE trial. Arthritis Rheum. 2006:54(3):702-10.

15. Tekaya R, Sahli H, Zribi S, et al. Obesity has a protective effect on radiographic joint damage in rheumatoid arthritis. Tunis Med. 2011;89(5):462-5.

16. Mikuls TR, Payne JB, Yu F, et al. Periodontitis and Porphyromonas gingivalis in patients with rheumatoid arthritis. Arthritis Rheumatol. 2014:66(5):1090-100.

17. Aletaha D, Alasti F, Smolen JS. Rheumatoid factor determines structural progression of rheumatoid arthritis dependent and independent of disease activity. Ann Rheum Dis. 2013;72(6):875-80.
18. Lindqvist $\mathrm{E}$, Eberhardt $\mathrm{K}$, Bendtzen $\mathrm{K}$, et al. Prognostic laboratory markers of joint damage in rheumatoid arthritis. Ann Rheum Dis. 2005;64(2):196-201.

19. Terao C, Yamakawa N, Yano K, et al. Rheumatoid Factor Is Associated With the Distribution of Hand Joint Destruction in Rheumatoid Arthritis. Arthritis Rheumatol. 2015;67(12):3113-23.

20. van der Heijde DM, van Riel PL, van Leeuwen MA, et al. Prognostic factors for radiographic damage and physical disability in early rheumatoid arthritis. A prospective follow-up study of 147 patients. Br J Rheumatol. 1992:31(8):519-25.

21. van der Linden MP, Batstra MR, Bakker-Jonges LE, et al. Toward a datadriven evaluation of the 2010 American College of Rheumatology/European League Against Rheumatism criteria for rheumatoid arthritis: is it sensible to look at levels of rheumatoid factor? Arthritis Rheum. 2011:63(5):1190-9.

22. Kim HH, Kim J, Park SH, et al. Correlation of anti-cyclic citrullinated antibody with hand joint erosion score in rheumatoid arthritis patients. Korean J Intern Med. 2010;25(2):201-6

23. Nishimura K, Sugiyama D, Kogata Y, et al. Meta-analysis: diagnostic accuracy of anti-cyclic citrullinated peptide antibody and rheumatoid factor for rheumatoid arthritis. Ann Intern Med. 2007:146(11):797-808.

24. Haugeberg G, Boyesen P, Helgetveit K, et al. Clinical and Radiographic Outcomes in Patients Diagnosed with Early Rheumatoid Arthritis in the First Years of the Biologic Treatment Era: A 10-year Prospective Observational Study. J Rheumatol. 2015;42(12):2279-87.

25. Burmester GR, Rigby WF, van Vollenhoven RF, et al. Tocilizumab in early progressive rheumatoid arthritis: FUNCTION, a randomised controlled trial. Ann Rheum Dis. 2016;75(6):1081-91.

26. Smolen JS, van Vollenhoven $\mathrm{R}$, Kavanaugh $\mathrm{A}$, et al. Certolizumab pegol plus methotrexate 5-year results from the rheumatoid arthritis prevention of structural damage (RAPID) 2 randomized controlled trial and long-term extension in rheumatoid arthritis patients. Arthritis Res Ther. 2015:17:245

27. Arnett FC, Edworthy SM, Bloch DA, et al. The American Rheumatism Association 1987 revised criteria for the classification of rheumatoid arthritis. Arthritis Rheum. 1988;31(3):315-24.

28. Neogi T, Aletaha D, Silman AJ, et al. The 2010 American College of Rheumatology/European League Against Rheumatism classification criteria for rheumatoid arthritis: Phase 2 methodological report. Arthritis Rheum. 2010;62(9):2569-81.

29. Bykerk VP, Massarotti EM. The new ACR/EULAR classification criteria for RA: how are the new criteria performing in the clinic? Rheumatology (Oxford) 2012;51 Suppl 6:vi10-5.

30. Saag KG, Teng GG, Patkar NM, et al. American College of Rheumatology 2008 recommendations for the use of nonbiologic and biologic diseasemodifying antirheumatic drugs in rheumatoid arthritis. Arthritis Rheum. 2008;59(6):762-84

31. Prevoo MLL. Modified disease activity scores that include twenty-eight-joint counts development and validation in a prospective longitudinal study of patients with rheumatoid arthritis. Arthritis Rheum. 1995:38(1):44-8.

32. Sokka T, Kankainen A, Hannonen P. Scores for functional disability in patients with rheumatoid arthritis are correlated at higher levels with pain scores than with radiographic scores. Arthritis Rheum. 2000;43(2):386-9.

33. Koh ET, Seow A, Pong LY, et al. Cross cultural adaptation and validation of the Chinese Health Assessment Questionnaire for use in rheumatoid arthritis. J Rheumatol. 1998:25(9):1705-8.

34. Bjelland I, Dahl AA, Haug TT, et al. The validity of the Hospital Anxiety and Depression Scale: An updated literature review. J Psychosom Res. 2002;52(2):69-77.

35. Li L, Wang H, Shen Y. Chinese SF-36 Health Survey: Translation, Cultural Adaptation, Validation, and Normalisation. J Epidemiol Community Health. 2003;57(4):259-63.

36. van der Heijde D. How to read radiographs according to the Sharp/van der Heijde method. J Rheumatol. 2000;27(1):261-3.

37. Jew NB, Hollins AM, Mauck BM, et al. Reliability testing of the Larsen and Sharp classifications for rheumatoid arthritis of the elbow. J Shoulder Elbow Surg. 2017;26(1):140-3.

38. Sterne JAC, White IR, Carlin JB, et al. Multiple imputation for missing data in epidemiological and clinical research: potential and pitfalls[J]. BMJ. 2009;338: b2393.

39. Ma JD, Wei XN, Zheng DH, et al. Continuously elevated serum matrix metalloproteinase-3 for $3 \sim 6$ months predict one-year radiographic progression in rheumatoid arthritis: a prospective cohort study. Arthritis Res Ther. 2015;17:289.

40. Xia YF, Yin RL, Fu T, et al. Treatment adherence to disease-modifying antirheumatic drugs in Chinese patients with rheumatoid arthritis. Patient Prefer Adherence. 2016;10:735-42. 
41. Salt E, Frazier SK. Predictors of Medication Adherence in Patients with Rheumatoid Arthritis. Drug Dev Res. 2011;72(8):756-63.

42. Kristensen LE, Saxne T, Nilsson JA, et al. Impact of concomitant DMARD therapy on adherence to treatment with etanercept and infliximab in rheumatoid arthritis. Results from a six-year observational study in southern Sweden. Arthritis Res Ther. 2006;8(6):R174.

43. Choy EH, Smith CM, Farewell V, et al. Factorial randomised controlled trial of glucocorticoids and combination disease modifying drugs in early rheumatoid arthritis. Ann Rheum Dis. 2008;67(5):656-63.

44. Orces $\mathrm{CH}$, Del Rincon I, Abel MP, et al. The number of deformed joints as a surrogate measure of damage in rheumatoid arthritis. Arthritis Rheum. 2002; 47(1):67-72.

45. Boers $M$, van Tuyl $L$, van den Broek $M$, et al. Meta-analysis suggests that intensive non-biological combination therapy with step-down prednisolone (COBRA strategy) may also 'disconnect' disease activity and damage in rheumatoid arthritis. Ann Rheum Dis. 2013;72(3):406-9.

46. Englund $\mathrm{M}$, Jöud $\mathrm{A}$, Geborek P, et al. Prevalence and incidence of rheumatoid arthritis in southern Sweden 2008 and their relation to prescribed biologics. Rheumatology (Oxford). 2010;49(8):1563-9.

47. Curtis JR, Singh JA. The Use of Biologics in Rheumatoid Arthritis: Current and Emerging Paradigms of Care. Clin Ther. 2011;33(6):679-707.

\section{Submit your next manuscript to BioMed Central} and we will help you at every step:

- We accept pre-submission inquiries

- Our selector tool helps you to find the most relevant journal

- We provide round the clock customer support

- Convenient online submission

- Thorough peer review

- Inclusion in PubMed and all major indexing services

- Maximum visibility for your research

Submit your manuscript at www.biomedcentral.com/submit

) Biomed Central 